\title{
Adenotonsillectomy: Effect on CRP Level in Children
}

\author{
Afsharpaiman $S^{1,}$, , Yosefi $\mathbf{J}^{2}$, Shahverdi $\mathbf{E}^{3}$, Kazemi $\mathbf{H}^{3}$ \\ ${ }^{1}$ Health Research Center-Pediatric Department, Baqiyatallah University of Medical Sciences, Tehran, Iran \\ ${ }^{2}$ New Hearing Technologies Research Center, ENT Department, Baqiyatallah University of Medical Sciences, Tehran, Iran \\ ${ }^{3}$ Students' Research Committee, Baqiyatallah University of Medical Sciences, Tehran, Iran
}

\section{Email address:}

safsharpaiman@yahoo.com (Afsharpaiman S)

\section{To cite this article:}

Afsharpaiman S, Yosefi J, Shahverdi E, Kazemi H. Adenotonsillectomy: Effect on CRP Level in Children. American Journal of Clinical and Experimental Medicine. Vol. 3, No. 5, 2015, pp. 275-278. doi: 10.11648/j.ajcem.20150305.23

\begin{abstract}
There is an increased risk of cardiovascular and cerebrovascular events in patients with obstructive sleep apnea (OSA). There are contradictory results about the correlation between serum CRP levels and OSA severity. The purpose of this work was to evaluate CRP level after adenotonsillectomy in children with clinical symptoms, suspected OSA. This cross sectional study was conducted between 20 March 2012 and 20 November 2014. The study group was composed of 98 children that indicated adenotonsillectomy due to clinical symptom of OSA. CRP were measured before and after surgery. Of total 98 children (52 males and 46 females) with an average age of $8.14 \pm 2.6$ years, 14(14.3\%), 29(29.6\%), 44(44.9\%), and 11(11.2\%) patients were with adenoid grade I, II, III, and IV, respectively and in aspect of tonsil grade, $8(8.2 \%)$ with grade I, 37(37.8\%) with grade II, 43(43.9\%) with grade III, and 10(10.1\%) were with grade IV. Comparison of the mean of CRP before and after surgery, based on preoperative adenoid grade showed a significant difference in grade III and IV before and after surgery. In aspect of tonsil grade, in grade I, II and III, the mean CRP before and after surgery showed significant difference too. We found that change of CRP level has relationship with the grade of adenoid and tonsil hypertrophy, and may be helpful marker for indication of adenotonsillectomy.
\end{abstract}

Keywords: Obstructive Sleep Apnea, C-reactive Protein, Adenotonsilectomy

\section{Introduction}

Obstructive sleep apnea (OSA) is characterized by repeated episodes of upper airway occlusion during sleep [12]. It is also characterized by collapse of the upper airway during sleep, recurring apnea, intermittent hypoxemia, and daytime sleepiness. The severity of OSA is determined by the number of apnea/hypopnea episodes per hour of sleep and is expressed as the apnea-hypopnea index (AHI). Based on the AHI, OSA can be classified as mild (AHI 5-15), moderate (AHI 15-30), and severe (AHI > 30) [3-4].The one of more reason of OSA in children is hypertrophy of adenoid and tonsils. OSA is an independent risk factor for hypertension, and is involved in the initiation and progression of other cardiovascular diseases [5-6].

C-reactive protein (CRP) is an important marker of inflammation and atherosclerosis [7-8]. Increased CRP levels have been shown to be a predictor for peripheral vascular disease and myocardial infarction [9-10]. Inflammation plays a role in the development of atherosclerosis and coronary heart disease [11]. Chronic inflammation and risk of atherosclerotic complications can be detected by elevated serum levels of CRP [9]. It has been shown in the report by Shamsuzzaman et al. that there is a significant relationship between AHI and serum CRP levels [12]. Several authors have studied the relationship between AHI and highsensitivity C-reactive protein (CRP) levels in OSA patients, but the results are contradictory [13-14]. Unfortunately polysomnography is not available in all centers for children to detect of severity of OSA. Considering the association between OSA and cardiovascular disease and the overlapping risk factors, we evaluated CRP, after adenotosilectomy in children.

\section{Materials and Methods}

\subsection{Patients}

This is cross - sectional study on ninety eight children with breasting problems that candidate for adenotonsillectomy in our center between 20 March 2012 and 20 November 2014. The indication for Adenotonsillectomy were diagnosed by an Ear, nose and 
throat (ENT) physician with 10 years of experience with considering the signs and symptoms of patients, and hypertrophy grading of adenoid and tonsils. CRP were measured by using latex agglutination test before surgery and 3 months after adenotonsillectomy. Patients were excluded if they had signs of infection such as common cold, pharyngitis and etc. or the underling disease.

\subsection{Statistical Analysis}

Data were analyzed using Statistical Package for Social Sciences (SPSS) version 16 (SPSS Inc. Chicago, IL) for Windows. Normal distribution variables (approved by onesample Kolmogorov-Smirnov test) were compared using independent sample t-test between the groups and paired sample t-test within the groups. Chi square test was also used to compare categorical variables in the two groups. P value of less than 0.05 was considered statistically significant.

\subsection{Ethical Considerations}

This study was approved in Ethics Committee of Baqiyatallah University of Medical Sciences and Health Services. Individuals were asked to sign an informed consent form before answering the questionnaire. All the terms of Helsinki declaration were considered and the personal information remained anonymous.

\section{Results}

In total 98 children (52 males and 46 females) with symptoms of sleep apnea who had undergone adenotonsillectomy, an average age was $8.14 \pm 2.6$ years. Table (1) shows the frequency of variables included: anorexia, apnea, snoring, and mouth breathing, drowsiness, nasal speech, and face changes, absence of school and laboratory findings before and after adenotonsillectomy. According to this table, there was a significant difference in frequency of most variables before and after adenotonsillectomy.

Table 1. Frequency of Variables before and after Adenotonsillectomy.

\begin{tabular}{llll}
\hline & $\begin{array}{l}\text { Before } \\
\text { adenotonsillectomy }\end{array}$ & $\begin{array}{l}\text { After } \\
\text { adenotonsillectomy }\end{array}$ & P Value \\
\hline Anorexia & $41(41.8 \%)$ & $\begin{array}{l}7(7.1 \%) \\
1(1.02 \%)\end{array}$ & 0.05 \\
$\begin{array}{l}\text { Apnea } \\
\text { Snoring }\end{array}$ & $7(7.1 \%)$ & $0.50 \pm 1.27$ & 0.02 \\
Mouth & $6.37 \pm 2.46$ & $1(1.02 \%)$ & 0.01 \\
breathing & $81(82.6 \%)$ & $1(1.02 \%)$ & 0.000 \\
$\begin{array}{l}\text { Drowsiness } \\
\text { Nasal speech }\end{array}$ & $46(46.9 \%)$ & $2(2.6 \%)$ & 0.01 \\
$\begin{array}{l}\text { Face changes } \\
\text { Absence }\end{array}$ & $20(20.4 \%)$ & $1(1.3 \%)$ & 0.000 \\
from school & $51(52 \%)$ & $3(3.06 \%)$ & 0.04 \\
\hline
\end{tabular}

The mean of CRP in all three age groups, and in both genders showed a significant difference before and after surgery. Table (2)

Table 2. The Mean of CRP before and After Surgery According to Age and Gender.

\begin{tabular}{lllllll}
\hline & & \multicolumn{3}{l}{ Gge } & & \multicolumn{2}{l}{ Gender } \\
\cline { 3 - 7 } & & $<7$ years & $\mathbf{7 - 1 2}$ years & $>$ 12 years & Male & Female \\
\hline \multirow{2}{*}{ CRP } & Before & $2.83 \pm 2.15$ & $2.46 \pm 2.27$ & $2.83 \pm 2.91$ & $2.38 \pm 2.19$ & $2.84 \pm 2.33$ \\
\multirow{2}{*}{ P Value } & After & $1.22 \pm 0.95$ & $1.39 \pm 1.53$ & $0.73 \pm 0.44$ & $1.12 \pm 1.16$ & $2.41 \pm 1.39$ \\
\hline
\end{tabular}

Of total 98 patients, $14(14.3 \%), 29(29.6 \%), 44(44.9 \%)$, and $11(11.2 \%)$ patients were with adenoid grade I, II, III, and IV, respectively and in aspect of tonsil grade, $8(8.2 \%)$ with grade I, 37(37.8\%) with grade II, 43(43.9\%) with grade III, and $10(10.1 \%)$ were with grade IV. Comparison of the mean of CRP before and after surgery, based on preoperative adenoid grade, did not show in grades I and II, any significant difference. In Grade III and IV CRP showed a significant difference before and after surgery. In aspect of tonsil grade, in grade I only CRP was not significantly different before and after operation, in grades II , III and IV, the mean of CRP before and after surgery showed a significant difference Table(3).

Table 3. Comparison of the Mean of CRP before and after Surgery Based on Preoperative Adenoid and Tonsil Grade.

\begin{tabular}{|c|c|c|c|c|c|c|c|c|c|}
\hline & & \multicolumn{4}{|l|}{ Adenoid } & \multicolumn{4}{|l|}{ Tonsil } \\
\hline & & I & II & III & IV & I & II & III & IV \\
\hline \multirow{2}{*}{ CRP } & Before & $1.46 \pm 0.86$ & $1.38 \pm 1.06$ & $2.97 \pm 2$ & $4.66 \pm 2.29$ & $1.39 \pm 0.62$ & $1.29 \pm 1.19$ & $2.95 \pm 2.04$ & $3.39 \pm 1.98$ \\
\hline & After & $1.53 \pm 2.37$ & $1.02 \pm 1.11$ & $1.27 \pm 1.15$ & $2.30 \pm 1.21$ & $1.25 \pm 1.77$ & $1.21 \pm 1.41$ & $1.28 \pm 1.05$ & $1.42 \pm 1.29$ \\
\hline $\mathrm{P}$ Value & & 0.92 & 0.07 & 0.01 & 0.03 & 0.02 & 0.01 & 0.04 & 0.05 \\
\hline
\end{tabular}

Comparison of the mean of CRP before and after surgery, based on preoperative clinical symptoms, revealed that CRP mean in patients with negative history of mouth breathing, nasal speech and face change showed no significant difference.

\section{Discussion}

C-reactive protein (CRP) is a marker of inflammation that has repeatedly shown promise as a potentially reliable biomarker of cardiovascular morbidity, also CRP may 
enhance inflammation, and promote thermogenesis [15-16]. Children with obstructive sleep apnea syndrome may have a raised CRP that decreased significantly following adenotonsilectomy [16-17].

In this study we found that after surgery in children with clinical symptom of OSA, CRP were reduced significantly $(\mathrm{P}=0.02)$ We also found that snoring, mouth breathing, anorexia, nasal speech, recurrent tonsillitis, sinusitis and otitis were reduced after surgery. Comparison of the mean CRP before and after surgery, based on preoperative grade of adenoid, showed that in grade three, and in grade four, CRP showed a significant difference before and after surgery.

In some studies [18-19], most common complaints of patients with respiratory disease caused by an enlarged tonsils were mouth breathing, and lack of concentration at school. They showed that in children with severe respiratory symptoms, CRP was significantly higher $(\mathrm{P}=0.01)$ and the adenotonsillectomy treatment of respiratory disorder markedly decreased CRP. ( $\mathrm{P}=0.03)$ In our study, mouth breathing and Nasal speech were the most symptoms of children and also decreases after surgery. We found that in greater adenoids and tonsils (grade III and IV), CRP was higher than in grade I, and II and after adenotonsillectomy was decreased more significantly. Guven et.al [20] demonstrated that sserum CRP levels were higher in children with respiratory disease that confirmed our findings. Kheirandish-Gozal et al [21] showed that CRP levels in children with respiratory symptoms caused by an enlarged tonsils were decreased after adenotonsillectomy. In our study serum CRP levels were decreased significantly after adenotonsillectomy too.

\section{Conclusions}

It seems in children with respiratory symptoms due to large tonsils, CRP increases and reduces with adenotonsillectomy, so can be helpful in determining need of surgery especially in the centers without availability of polysomnography in children with higher grades of adenoid and tonsils.

\section{References}

[1] Brouillette RT, Fernbach SK, Hunt CE. Obstructive sleep apnea in infants and children. The Journal of pediatrics. 1982; 100(1): 31-40.

[2] Amin RS, Carroll JL, Jeffries JL, Grone C, Bean JA, Chini B, et al. Twenty-four-hour ambulatory blood pressure in children with sleep-disordered breathing. American journal of respiratory and critical care medicine. 2004; 169(8): 950-6.

[3] Gozal D. Sleep-disordered breathing and school performance in children. Pediatrics. 1998; 102(3): 616-20.

[4] Shahar E, Whitney CW, REdline S, Lee ET, Newman AB, Javier Nieto F, et al. Sleep-disordered breathing and cardiovascular disease: cross-sectional results of the Sleep Heart Health Study. American journal of respiratory and critical care medicine. 2001; 163(1): 19-25.
[5] Nieto FJ, Young TB, Lind BK, Shahar E, Samet JM, Redline S, et al. Association of sleep-disordered breathing, sleep apnea, and hypertension in a large community-based study. Jama. 2000; 283(14): 1829-36.

[6] Peppard PE, Young T, Palta M, Skatrud J. Prospective study of the association between sleep-disordered breathing and hypertension. New England Journal of Medicine. 2000; 342(19): 1378-84.

[7] Ferranti SD, Rifai N. C-reactive protein: a nontraditional serum marker of cardiovascular risk. Cardiovascular Pathology. 2007; 16(1): 14-21.

[8] Baguet J, Pepin J, Hammer L, Levy P, Mallion J. [Cardiovascular consequences of obstructive sleep apnea syndrome]. La Revue de medecine interne/fondee par la Societe nationale francaise de medecine interne. 2003; 24(8): 530-7.

[9] Kokturk O, Ciftci TU, Mollarecep E, Ciftci B. Elevated Creactive protein levels and increased cardiovascular risk in patients with obstructive sleep apnea syndrome. International Heart Journal. 2005; 46(5): 801-9.

[10] Sharma S, Mishra HK, Sharma H, Goel A, Sreenivas V, Gulati $\mathrm{V}$, et al. Obesity, and not obstructive sleep apnea, is responsible for increased serum hs-CRP levels in patients with sleep-disordered breathing in Delhi. Sleep medicine. 2008; 9(2): 149-56.

[11] Visser M, Bouter LM, McQuillan GM, Wener MH, Harris TB. Elevated C-reactive protein levels in overweight and obese adults. Jama. 1999; 282(22): 2131-5.

[12] Shamsuzzaman AS, Winnicki M, Lanfranchi P, Wolk R, Kara $\mathrm{T}$, Accurso V, et al. Elevated C-reactive protein in patients with obstructive sleep apnea. Circulation. 2002; 105(21): 2462-4.

[13] Ridker PM, Cushman M, Stampfer MJ, Tracy RP, Hennekens $\mathrm{CH}$. Plasma concentration of C-reactive protein and risk of developing peripheral vascular disease. Circulation. 1998; 97(5): 425-8.

[14] Sanders MH. Elevated plasma C-reactive protein and increased cardiovascular/cerebrovascular risk in sleep apnea patients. Article reviewed: Elevated C-reactive protein in patients with obstructive sleep apnea (a brief rapid communication). Sleep medicine. 2002; 3(5): 449.

[15] Gozal D, Kheirandish-Gozal L, Bhattacharjee R, Kim J. Creactive protein and obstructive sleep apnea syndrome in children. Front Biosci (Elite Ed). 2012 Jun 1; 4: 2410-22.

[16] Li AM, Chan MH, Yin J, et al, C-reactive protein in children with obstructive sleep apnea and the effects of treatment. Pediatr Pulmonol. 2008 Jan; 43(1): 34-40.

[17] Teo DT, Mitchell RB. Systematic review of effects of adenotonsillectomy on cardiovascular parameters in children with obstructive sleep apnea.Otolaryngol Head Neck Surg. 2013 Jan; 148(1): 21-8.

[18] Guilleminault C, Kirisoglu C, Ohayon MM. C-reactive protein and sleep-disordered breathing. Sleep. 2004; 27(8): 1507-11.

[19] Zouaoui Boudjeltia K, Van Meerhaeghe A, Doumit S, Guillaume M, Cauchie P, Brohée D, et al. Sleep apnoeahypopnoea index is an independent predictor of highsensitivity C-reactive protein elevation. Respiration. 2006; 73(2): 243-6. 
[20] Guven SF, Turkkani MH, Ciftci B, Ciftci TU, Erdogan Y. The relationship between high-sensitivity C-reactive protein levels and the severity of obstructive sleep apnea. Sleep and Breathing. 2012; 16(1): 217-21.
[21] Kheirandish-Gozal L, Capdevila OS, Tauman R, Gozal D. Plasma C-reactive protein in nonobese children with obstructive sleep apnea before and after adenotonsillectomy. Journal of clinical sleep medicine: JCSM: official publication of the American Academy of Sleep Medicine. 2006; 2(3): 301. 